\title{
The Peculiarities of Text/Discourse Deixis in the English Language
}

\author{
Mahmudova Shafagat Abdulla ${ }^{1}$ \\ ${ }^{1}$ Azerbaijan University of Languages (AUL), Baku, Azerbaijan \\ Correspondence: Mahmudova Shafagat Abdulla, Azerbaijan University of Languages (AUL), Baku, Azerbaijan. \\ E-mail: shafagat.m@gmail.com
}

Received: January 18, 2020 Accepted: March 10, 2020 Online Published: March 18, 2020

doi:10.5539/ijel.v10n3p141

URL: https://doi.org/10.5539/ijel.v10n3p141

\begin{abstract}
The text/discourse deixis is found to be used in the English language to express the interpersonal relationships involved between the speaker and listener in conversation. The article explores some peculiarities of text/discourse deixis in the English language. It is noted in the article that while the traditional categories of the deixis are the most obvious examples, there are other types of deixis that are widely available. These categories are for the first time discussed by Fillmore and Lyons. These categories are categories of social deixis and text/discourse deixis. Our article deals with the use of the text/discourse deixis in English. The article also covers discussion of linguistic views of scientists in this field. We think that urgency of the work just lies in the theoretical problems discussed in the article. The article is also of both theoretical and practical importance in the view of learning English and developing the science of linguistics as a whole.
\end{abstract}

Keywords: deixis, text/discourse deixis, text linguistics, deictic expressions, egocentric transmission

\section{Introduction}

As it is known human speech is realized in a certain situation, condition and environment. In order to establish intercourse with one another human beings use language and the first and initial function of a language is to transfer a certain piece of information. This is called a transactional function in linguistics. Human beings give information to one another by order, request and instruction to one another by means of the language. The whole scope of actions carried out as a result of these processes in the language is called context. It becomes clear from the context, who is pointing to somebody or something by special words which are called deictic words: here, there, I, you, he, down, up etc. Deictic words just carry out deictic functions. The category of pronouns, as the system of deictic words, causes great interest. It is not occasional that grammatical degree attracted the attention of soviet investigators and the investigators including other countries as well. In the English language the authors of grammatical dialects and other works have not forgotten this difficult and interesting part of linguistics. Nevertheless, the origin of different degrees of pronouns, their formation and development have not been determined up to now. In modern linguistics deixis gives the meaning of "to indicate", "to show", "to point to". This word traditionally is as to the semantics nearer to the "indexical expression" in linguistics. In the English language, particularly demonstrative pronouns carry out this deictic function. Deixis is a means, uniting semantics with pragmatics, because, language expressions are set up by means of pragmatic substitutions. Service to determine the roles of participants of the communication mainly falling on the pronouns, is the meaning or function of language unit, expressed as a lexical and grammatical means. Deixis serves to actualize the denotative contents of the expression, components and situation of the text. In modern investigations deixis is studied together with semantics and pragmatics.

The concept of the deixis is related to a class of language units that are used to point to the elements of the situational or discourse context. These include both the interview participants and the location and time of the current conversation. The category of deixis is one of the most important categories of language communication. The universality of the deixis is measured by the fact that the speech process is not imagined without the units: the utterance can not be without space or time. The anthropocentric paradigm of contemporary linguistics allows for such a hypothesis that the deixis is a specific natural creation of egocentrism, so that any utterance or speech made by the speaker is a product of its communicative-cognitive experience. Deixis is a kind of reference. The nature of this reference, its communicative functions, the language development have long been in the focus of linguists. Deixis is often identified with the demonstrative pronouns /this/ and /that/ because of its etymological meaning of pointing. Deictic words and the gestures accompanying them are parts of the language system to 
create a reference. From the point of view of the basic philosophy, the pointing is required for reference, deictic expressions are defined by non-linguistic motion. The demonstrative pronoun /this/, in the expression of/this is a star/is defined by non-linguistic motion. This viewpoint confirms the deictic expressions by a non-linguistic reference, and this reference is identified with the deictic expression, because it is accompanied by non-linguistic action or gesture. But this idea may not always be true. Because the deictic expression does not identify the reference with extrolinguistic means, it is more desirable to identify the reference in the form of a deictic, under the deictic description by saying something about it. , this idea can not be considered to be correct either that the deictic expressions are expressed by non-linguistic movements indicating the reference. Moreover, the idea of the gestures being non-linguistic identifies the language with the speech, but speech is just one of the language means. For example, we can prove the language used by the deaf.

Traditionally, the function of the utterance is understood under the deixis coinciding with spatial-time coordinates of the speech act. The most important aspect of the deixis concept is that it provides the communication effectiveness with the general background knowledge of the speaker. When language is used, language and context are closely connected with the help of the deixis in the language system.

The topic of our article text/discourse deixis is grammaticalized through the pronominal system. A set of personal pronouns (e.g., he, she, you, etc.) function as one of the basic ways of expressing text/discourse deixis in the English languages. In this paper, I intend to make analysis of the peculiarities of the text/discourse in the English language. This paper explores the investigation of peculiarities of text/discourse deixis in the English language. Different from the traditional study of deixis in the English language, the study of the reasons why the use of deixis, its kinds are important in the language, different opinions of linguistics about the usage of text/discourse deixis, can be considered the foundation of the research. One of the aims and objectives of our approach to the research, finds its reflections in the aspect with which we investigate the theme.

The main objectives of the investigation are to determine the text/discourse deixis, its referring to the phenomenon where in understanding the meaning of certain words and phrases in an utterance requires contextual information, which concerns the encoding of reference to portions of the unfolding discourse in which the utterance is located.

\section{Methodology of the Study}

The corpus of this research has been taken from different sources such as newspapers, every day conversation, English fiction. It is necessary to state that the newspapers and the fiction are possible to be seen online. A representative sample of the sources has been conducted as a preliminary pilot study. It is noteworthy to mention that the fiction and the newspapers having been chosen as sources have been published for specific purposes. The samples that introduce text/discourse have been selected from different sources addresses a large variety of audience. It is noteworthy to mention the fact that in the investigation of the problem may be considered completely for it is not possible to cover all the study by using one method. It is obviously clear that study of deixis in English is considered to be a new branch in linguistic study. That is why the study of text/discourse is needed to investigate deeply.

The following has been chosen during the investigation:

- The method of tenacity within the pragmatic model;

- To follow the systematization of the theory and practice the method of dedication is used as well

- A qualitative analysis of the most frequently used text/discourse in English.

- For the successful realization of the goal structural-semantic, pragmatic and experimental methods have also been used in the analyses of the practical language materials.

\section{Theoretical Overview}

A discussion on the peculiarities of the text/discourse deixis demands at least a minimum of introduction to some basic concepts and terminologies found in the field of deixis. What follows then is a brief discussion of some basic concepts related to the subject matter of the paper.

\subsection{The Concept of Deixis}

The concept of deixis is often referred to in the grammar categories in linguistics. Although the grammatical categories related to the grammar are not entirely functional, it is clear that some analogies are true. One of them is the category of deixis. As you know, language is objective-subjective, i.e., in one hand, the language acts as a means of communication of specific language carriers as a product of objective, public and certain linguistic environment. On the other hand, the human language is subjective, because it only functions with the help of 
individuals and obeys the individual's personal demands.

The opposition of the socio-objective and individual-subjective characteristics of the language and their interaction are revealed and realized primarily in the language dictionary by the existence of a deictic microsystem that serves to the speech act. Mutual communication between the speech act and its pragmatic aspects implies the existence of specific words in the language system.

These linguistic elements, along with identifying the parts of the discourse during constant change of referents, connect the text with the speech situation and eventually play a role as a means of communication between language and reality. Linguists' stress that communication between people is impossible without the means of this language. However, this problem was solved by a language, it means that the language created a number of signs. These signs were interpreted differently by different researchers. Bühler (1990), Fillmore (1971b), Lyons (1975) and others dwelled on these elements as the deictic words, Yespersen, Jacobson and others named these elements as shifters, but Pierce and others considered them as indexes (Yespersen, 1958; Jakobson, 1971; Pierce, 2001). Vaynrix and others used these terms as speech pointings (Vaynrix, 1970, pp. 177-179).

Linguistics usually deals with three types of deixis: person, space, and time. Yule refers the elements as (I, me, you, him) to person deixis which refer to the person (Brown \& Yule, 1988, p. 87). He refers the space-like elements (here, there, this, the) to space deixis, temporal semantic words (now, then, last week) to time deixis. As we mentioned above, while the traditional categories of the deixis are the most obvious examples, there are other types of deixis that are widely available. These categories are for the first time discussed by Fillmore and Lyons. These categories are categories of social deixis and text/discourse deixis (Fillmore, 1971b; Lyons, 1975).

Also, the completeness of a complete set of imagery, not of an image taken, is a requirement for any scientific research. Thus, the text should be described in detail; in one hand, the information in the word material should find itself at one or another level of the image; on the other hand, the majority of these levels should be set in a single continuous sequence, as Benvenist states that the units of each level are directly related to the subsequent higher level units, i.e., the sequence of differential sign, phoneme and word coding in the language (Benvenist, 1974, p. 111). We want to briefly explain the concept of text and its types before commenting on the text. There are several types of text terminology available. On the one hand, in the opinion of the speaker, the concept of the text is used to designate a statement containing one or more sentences containing the finished thought. On the other hand, stories, novels, articles, and so forth are called with this term. According to the generally accepted view, the text is understood as a specific structure consisting of a number of units, which has connections, exertion, and internal organization.

Thus, the essential precondition for constructing text linguistics as a science is the identification of the levels for each of the objects it describes, so that the corresponding texts, starting with the text, and the text can be delivered into the extent that the text is directly related to social practice. As it is known, linguistics is the subject of the comprehensive study of sentence knowledge and linguists are taking steps to determine the place of the text or the complex syntactic whole in the syntactic system. Based on the concepts in this field, the essence of the text is based on the principle of the fullness of the sentence as well as the nature of the language as well as the analysis of its activities. Even the function of the language is separated by the text function, and this function implies the ability to transmit language information. On the other hand, linguists have come to the conclusion that while analyzing concrete events within the context of textual studies, these events are also considered in sentence syntax, and this is due to a number of reasons, including the ability to convey the textual function of separate sentences, namely, a textual event, as well as the possibility of relationships having the inter-text peculiarity (e.g., anaphoric link).

We will try to clarify both of the deixis because we have a text and a discourse in our study. There are deictic manifestations that appear to be a very lexical-grammatical link between the text components, which are in line with the contextual context in which the text exists. Of course, the text cannot be understood unless someone accepts these deictic elements correctly with the relevant (relevant) manifestations of their situation. The semiconductor research of verbal words should encourage a thorough investigation of the various aspects of their functioning as a means of forming a text-discourse of their language in their speech. From the research we see that in this direction the study of the role played by deictic pronouns in the structural integrity of the discourse is in the foreground.

Kirvalidze emphasizes the importance of the role of person in this field by studying the textuality of the deictic means on the English language material. In his opinion, the person deixis "I" becomes more apparent during the egocentric transmission of the text or discourse (Kirvalidze, 1991, p. 165).

For example: /The accident occurred on a Friday afternoon, as I was driving home. The traffic was moving 
quickly along the Santa Teresa freeway and my own little Volkswagen was running well though it's fifteen years old. I was feeling good. I had just solved a difficult case, and I had a cheque in my handbag for our thousand dollars./

As an organizational center of this text, the " $P$ " unites the entire discursive space around it. In such a case, the functional feature of the deictic element "I" extends to the discourse level, and the relationship between its parts is created. In general, there is a relationship between the type of "I" and the type of discourse in the text: the expression of the verb in the speech, only the subject of the speech, and also the form of the speech creates the image of the subject. As a result, the whole "I" is divided into different semantic layers and this division is accompanied by the transmission from one time to another. Thus, the separation of different semantic layers from element " $P$ " occurs with the substitution of that element on the subjective reference line. In the discourse "I"-now-here becomes a zero-reference point "I". This lexicon contains certain cognitive information. With the change in the coordinate of the text, the "I-there-then" separates the word " $P$ " from the subject. Accordingly, we say, "I" acts as the subject of propositional origin or as the subject of proposition. During the appearance of the text itself, discourse is formed around the " $\Gamma$ " derivative, as numerous hierarchical structures. This structure identifies the "I" element in every aspect of its development in its distinctive manifestations. Consequently, the detection of the relevant referent occurs only in the discourse.

Lyons commented on the use of deictics in his definition of a canonical situation of utterance as follows: "The grammaticalization and lexicalization of deixis is best understood in relation to what may be termed the canonical situation of utterance: this involves one-one, or one-many, signaling in the phonic medium along the vocal-auditory channel, with all the participants present in the same actual situation able to see one another and to perceive the associated non-vocal paralinguistic features of their utterance, and each assuming the role of sender and receiver in turn" (Lyons, 1975, p. 165). There is much in the structure of languages that can only be explained on the assumption that they have developed for communication in face-to-face interaction. This is clearly so as far as deixis is concerned.

\section{Review of Literature}

Lyons (1975, pp. 85-97), Fillmore (1971a, pp. 69-94), Levinson (2004, pp. 54-96), and other scholars have made a considerable detailed study on deixis. They distinguish two of the five types of deixis catagory - discourse and text. Discourse deixis is closely related to the lexical and grammatical elements of any speech section. Having formal elements of the text. Lyons has a detailed study of deixis in his "Semantics" published in 1977, mainly discussing person, space and time deixis. Lyons' definition of deixis (Iyons, 1975, pp. 123-129) is considered to be the most authoritative up to now. He also points out the phenomenon of deictic projection a derivative use of deixis, but he makes no elaborate description of it.

According to Mammadov (2014, p. 8) discourse deixis has strong pragmatic and cognitive potential with the goal of creating a specific environment over the event it covers.

Lyons (1975, p. 636) states that the term deixis is now used in linguistics to refer to the function of personal and demonstrative pronouns, of tense and of a variety of other grammatical and lexical features which relate utterances to the spatiotemporal co-ordinates of the act of utterances. Fillmore's view is similar to Lyons' claiming that the interpretation of deixis makes reference to a canonical context, i.e., the speaker-centered context. He focuses on the study of space, time, social and discourse deixis and puts forward that deixis may have both deictic and non-deictic usages. Levinson summarizes both philosophical and descriptive approaches to deixis in his "Pragmatics" published in 1983 (Levinson, 1983, pp. 156-163).

Fillmore calls these categories the "major grammaticalized types" of deixis. In addition to person, place and time deixis, there are two other types of deixis that are similarly pervasive in language use. These categories are: "Social deixis" and "text/discourse deixis", which were first discussed by Fillmore and Lyons.

Chafe points out that discourse deixis concerns the use of expressions referring to a part of the discourse. In discourse deixis, there are many words and phrases in English that indicate the relationship between utterance and prior discourse such as: but, therefore, in conclusion, to the contrary, however, besides, after all etc. (Chafe, 1994, p. 392).

The ratio of the text's integrity and integrity to deixis category is examined in Muhlhazer's research. In this case, deixis is regarded as a category of grammar (Muhlhauser \& Harre, 1990, p. 156). The author considers discourse deixis as a grammatical category, which also includes references to the characteristics of the utterance state. English language articles are viewed as markers of old and new information. A definite article is used as a marker that delivers the old information, while the indefinite article is used as a marker for delivering new 
information. The author describes the text encryption system with the help of the article based on the analysis connecting with the text (Muhlhauser \& Harre, 1990, p. 167).

Sital states that to use some expression within some utterance to refer some portion of discourse, that contains the utterance is called discourse/text deixis.

According to Suhair Adil Abdulameer discourse deixis describes deictic expressions which indicate prior oe succeeding parts of the discourse. He points out that the words and phrases that indicate the relationship between an utterance and the prior action is a kind of commentary on the text or conversation by the speaker.

Kirvalidze emphasizes the importance of the role of person in this field by studying the textuality of the deictic means on the English language material. In his opinion, the person deixis "I" becomes more apparent during the egocentric transmission of the text or discourse.

\section{Results and Discussion}

In the American-English linguistics, the main concept is the discourse that expresses various aspects of the text. The discourse is the text spoken by (Connected speech). In this sense, the discourse differs from the text taken and understood as the formal grammatical structure. Contemporary text linguistics examines the structure of the text with a certain hierarchical integrity and the semantic-functional and discursive relationships defined in those rules. Discourse coherent textual research is part of a science as a whole within the philology. When it comes to discourse, the coherent text that the speaker has directed to his interlocutor is intended, or in other sense understood as the result of an interactive process in a social context. Discourse in text linguistics is considered paradoxical. The text is an oral idea of the event of communication, and the discourse is the text in the event of the event, it is a lifelong conversation, that is, a language spoken in active communication. According to Benvenist, "the discourse is the language spoken by the speaker". Discourse/text deixis category refers to the expressions used in the text/discourse, and also includes the statement itself (Benvenist, 1974, p. 104, 174). Discursion directs the referencing to the discursive part of the speaker in connection with the current environment. They refer to the discourse as a text hypothesis. That is, discursive lexical means the lexicon. Discursion refers to expressions that are played as part of a discourse. These expressions also include the words themselves. This means they are not, they do not place any participants in the discourse, nor do they point to it. The discourse deixis facilitates the understanding of the dependence of the semantic integral part of the text, and this dependence is explicitly understood by the sender.

Let's take a look at the microtext below, and the examples are given in black font:/Nigerian President Goodluck Jonathan will not be attending this week's African Union Summit, his office has confirmed. Even though discussions on terrorist group Boko Haram feature high on the agenda across the African continent this year. Nigeria will be represented by Foreign Minister Aminu Wali. City Press reported on Thursday. Jonathan is currently touring Nigeria to campaign before the country's elections, which are due to take place on February. Analysts say this is one of the hotly contested elections./ Black fonts serve as a deixis, but they do not point out any participant in the discourse. The /here/ and /there/ phrase for the discourse is also associated with the temporal measurement of discourse. /There/ associates with commonly used information, and /here/ provides information about the word spoken. The /This and that/ hierarchy are also the elements of the discourse. /This/ part of the previous discourse refers to the next part of /that/ and /then/.

For example:/This is what I tell you./

/That was the only word she could speak German./

/How much is this fish, sir?/

IJust seven hundreds.

IHow much are these all?

IAll becomes three-thousand-seven hundreds.

The words this/these are deictic expressions in the utterance, because they relate to the earlier part of the discourse. In our point of view, the fact that the place and time adverbs are directly linked to the situation in which the text is being processed is also a specific discursive function. When we look at it, we see that many linguists point to the role of the text-forming elements of these deictic elements. For example, Ehlich considers the role of intercourse interactions in English, emphasizing time and place adverbs in this function (Ehlich, 1983, p. 98). Halliday has shown the textual features of the present, then, here, and there/adverbs. They conducted researches on the discursive essence of adverbs /here and there/ (Halliday, 1972, p. 234). He notes that these adverbs have space, sign and discursive features in English, and emphasizes that the adverb is an exponential 
essence in addition to these features. Let's look at the following examples. In these examples, we find that the adverbs /here and there/ match the current situation within the discourse and perform the deictic function: /My heart was banging the loudly as I rang the bell of the house. When the door finally opened, I just stood there with my mouth open. Wrong man. This man was tall and fat, with blue eyes and red hair./Mrs Spurrier, the police are here very good at their job. I'm sure they are doing everything possible./I'm not sure. But I have to fly back to Denver now. My husband is very ill and I need to get home. I can not go until I know someone here is looking into this. Pleasel.

Parallelism is observed in the structures where the adverbs/here and there/are processed. Both of them perform the function of pointing to a subject, person, or event. The difference between them is that the adverb is close to the adverb, and the adverb is an indication of the proximity. The combination of the adverbs /here and there/within the discourse further strengthens the opposite between them. For example: /Dressed up in white flannels I went over to his lawn a little time after seven and wandered around pretty ill I did not know commuting train./ All available definitions of the deixis refer to the speech act. They are also confused by the impression that it is supposed to belong only to pragmatics and it is not possible in the artistic text. The idea that limits the opportunities of the deixis is only confirmed by the fact that his research is very important in the text, especially in the artistic text. The works on this research are not satisfactory. These works, which are devoted to the study of the text deixis, are mostly centralized only on pronouns, which limits considerably the scope of research and the results obtained. Deixis in narrative depends on the context, moment and relation. Each language has many words known as deixis. Such words as I/you, here/there, now/then, this/that, yesterday/today/tomorrow/ - used in narrative refer to the previously mentioned person, space, and time.

The classification of the discourse deixis is divided into two major categories: verbal and non-verbal discourse deixis. Non-verbal discourse deixis (facial expressions and gestures) is considered non-linguistic. Verbal discourse deixis can be classified in two subcategories, oral and written discourses. Oral and written discourse can be divided into two major categories: the monologue and dialogue discourse, depending on the nature and role of interlocutors' mutual affiliations. Monologue discourse is based on less communicative activity without the intervention of a person. Dialogue discourse, on the other hand, consists of statements made between one or more interlocutors (Nida, 1946, p. 165). Dialogue discourse is often called active language. Now linguists prefer to call it a discourse rather than a language at a specific moment and condition. It can also be added that as the interaction with the semiotic plane is considered to be a motion involving the immediate involvement of linguosemiotic agents, it is also a factor that causes the discourse to become widespread. The deictic words in the discourse are called //who, where, when/. It is very difficult to interpret the simplest deictic sentence /I am here now $/ /$. Explaining the meaning of this sentence requires us to know who $/ I /$ is, what frame of development of the /am/ and /now/ expressions, and the precise location of /here/ here. Without the content, this sentence has only a lexical meaning, but there is no semantic content. Content relates to place and time, opportunity, social roles, demographic diversity and so on, in other words, text parts covering particular sections of narratives at any particular moment in the text (Benvenist, 1974, p. 159).

The researchers say that the term "deictic window" is much more commonly used than the word "content", but the word "deictic window" refers to the same element of the story as space, time and psychological coordinates create perspectives in the world of transportation. The text of the Deixis Mode of Text, written by Demarsky is commendable (Demarsky, 1999, p. 89). However, less space is available for this mode. His job has quite another purpose. Deixis and textual terms are synonymous with text and parts of the text. Narrative deixis or deictic project is associated with transport. This is the second (additional) deixis.

Minimal research in the country linguistics dedicated to the text-forming role of the deixis gives them a special actuality. A lot of research has been done on this issue both in domestic and foreign linguistics.

Despite the diversity of approaches and positions on the issue, they eventually testify to the accuracy of assumptions about the role of deixis in the artistic text. The semantic universality of the subjective and spatial — time contradictory text is derived by Demarsky as the deictic mode of the text (Demarsky, 1999, p. 167) On this subject, Demarsky speaks of the narrative's second deixis. In the study of Demarsky's research, it is also referred to as the narrative deixis and deictic project (Demarsky, 1999, p. 156). Obviously, Demarsky keeps the term of the text mode in his work. He thinks that the reader's ability to set up a fairly clear model of the world described here is directly dependent on the opportunity or non-opportunity. Behind these features is the general sign of the text, that is, the main subjective and spatial-time certainty, which constitutes its reference, and above all, conceals a sign of uncertainty (Demarsky, 1999, p. 167). Indeed, precise space-time coordinates, precise localization of the event create a feeling of its real existence. The precise dates at the beginning of the works, the exact names of places and people create convincing images, but the fiction itself represents the model of real life. 
Only the initial signs do not make sense of events, characters, or space. The novel can include new titles throughout the work. All of this contributes to the sense of reality. We can refer to Bakhtin for proof. In Baktin's research, there are moments that are artificially valuable to human beings and all spatial, time and meaningful relationships. This valuable orientation around the human being and the sealed world create its aesthetic reality. Space-time frame precisely depicts the event described in time and space. The more accurate the localization is, the more convincing it seems to be (Bakhtin, 1986, pp. 80-160). In Demarsky's opinion, the requirement for the definition of chronotropic and subjective reference has any kind of ontological features and, indeed, the transmission of speech. He calls his deictic mode a functional-semantic category (Demarsky, 1999, p. 212). When considering the role of the deixis in the creation of the text, it is necessary to focus on the concept of Ustin. Ustin devoted his several monographs to the creation of a deictic mechanism of the text. He creates his own model of textuality based on this mechanism. He examines various functional elements separately in a single deictic system and makes it a target, and then form a functional whole that leads them to a single point (Ustin, 1995, p. 7). His text-forming model incorporates the culturogen deictic and the deictic mechanism of pronouns of the artistic text. Pronouns are located along the sphere of the deictic mechanism horizontally. The author gives the description of the open-pronoun deictic and secret culturogen deictic mechanism, which directly affects the depth of the text. However, the highest degree of activity of the text-forming is detected (Ustin, 1995, p. 9). Ustin's culturogen deictic mechanism is connected with synchronic and diachronic plans of the culture. The deep-seated plan of the text develops in its own order and has a synchronic and diachronic status. Deixis creates this depth from its historical context. Ustin emphasizes how the classic text draws the internal and historical structure of the ancient text on itself. His text-forming deixis takes place as a manifestation of man's cultural values in the artistic text. It is related to the functionality of the pronouns in the text. However, the author does not refer the spatial and time pronoun adverbs to the pronoun deictic mechanism, nor does he include the other traditional deictics, such as prepositions, deictic adjectives and adverbs, action verbs and nouns formed from verbs this mechanism. All of these carry out the function of deixis, and they can enrich the pronoun deictic text-forming mechanism in the concept of Ustin (Ustin, 1995, p. 78). Foreign linguists' research devoted to the text deixis differs from having a broader range. In Ustin's work, the relationship between the text and the recipient is examined and the history of this important understanding is investigated in the history of literature. Based on the views of Bakhtin, the author states two events in his artistic work, one of which is mentioned in the work, and the other is a direct narrative event (Bakhtin, 1986, 125-145). Time and space relations between them also arise in different places and at different times. These two events are united in literary works (Ustin, 1995, pp. 189-190). It should be noted that the author cites from Buler and considers the anaphora one of the kinds of deixis (Ustin, 1995, p. 194).

Linguists and philosophers have adopted the concept of deixis in the role of the coding of spatial-time contexts and the role of subjective coding in the speech. Deixis is such a phenomenon that the trilogy between the linguistic systems here goes to the foreground with the subjectivity and context of the coding, which occurs with the help of lexical and grammatical means. Deixis consists of semantic and pragmatic elements. It also has a dual aspect-shape and functional aspect. The author includes the deixis category the traditional three-kinds: space, time and person deixis. The ratio of the text's integrity and integrity to deixis category is examined in Muhlhazer's research. In this case, deixis is regarded as a category of grammar (Muhlhauser \& Harre, 1990, p. 156). The author considers discourse deixis as a grammatical category, which also includes references to the characteristics of the utterance state. English language articles are viewed as markers of old and new information. A definite article is used as a marker that delivers the old information, while the indefinite article is used as a marker for delivering new information. The author describes the text encryption system with the help of the article based on the analysis connecting with the text (Muhlhauser \& Harre, 1990, p. 167). Thus, an article as a deictic unit can carry out the function of an encrypted and connected element in the text. Deixis plays a key role in placing and maintaining the information on the discourse. Under this terminology, the function of the discourse level is understood. This does not depend on whether its formal encryption can take place at the level of subordinate clause and participial construction. This term is used to summarize lexical, grammatical and syntactic means (Muhlhauser \& Harre, 1990, p. 178).

It should be noted that the author treats the discourse or the text deixis as the main type of deixis, which is usually identified as the occurrence of the main and time deixis. The main deixis includes person, space, and time coordinates (Muhlhauser \& Harre, 1990, p. 213).

Discourse deixis is also called as text deixis. It involves the development of expressions within the context. When deixis is used for rhetorical purposes, it is called discourse deixis. The second person is used in the discourse deixis. Discourse $=$ text + situation, text $=$ non-situational discourse. Text is a feature occuring in the 
forms of writing or speaking, listening, and reading. When we analyze it, we analyze the product of this process, and the term text refers to the product itself (Ustin, 1995, p. 127).

Consider the following example:

/ For two years I will have to interact with a new system, being part of it. This is a dilemma: on one side, I am not inclined to forget all the values and tastes that I had before. The trade-off between those two opposite tendencies showed me at least, my home should reflect my personality./

Grenoble's research work was carried out in the traditional plan for distinguishing deixis and anaphora. The difference is the development of pronouns, since the canonical case can be substituted for the anaphoric pronoun (Grenoble \& Matthew, 1996, p. 123).

Compare:

/ A man walked into the hall. He had a bag in his hand. I

(A man entered the hall and had a bag in his hand).

At this time, the deictic pronoun points to the referent in the extralinguistic text. The author clarifies the deictic and anaphoric usage of the discursive deixis. Discursive deictics provide links between texts, co-texts, combinations and contents which are key concepts in collecting of discursive information. The deictics can carry the deictic function in one sense, an anaphoric function in another sense. As a result of the deixis research in the text, the theory of deictic displacement has occured. By agreeing with this theory, the reader's cognitive approach to the content of the story is common or realistic. The reader frequently cognizes the context of the narrative world and interprets the text from this point of view.

The cognitive position implies the following: when someone reads the transcript as read, then it must be cognitive in the narrative world. The location serves as a center to interpret the sentence throughout the story world. The terms here and there are deictic terms that refer to conceptual location. This is a deictic center. The sharp focus does not stay static in the story, it acts as a storytelling.

Thus, the research of deixis has its own history. Different ideas about his role in the text can be accepted. But all studies confirm that the deixis plays an important role in the text, and it is multilateral.

\section{Conclusion}

Having studied the peculiarities of text/discourse deixis in the English language, we may come to the conclusion that deixis serves to actualize the denotative contents of the expression, components and situation of the text.

We have found out that in the modern linguistics by the term of "deixis" mainly are mentioned demonstrative and personal pronouns, some adverbs, grammatical tenses, including other lexical units and grammatical markers, being considered fitful to the place in which the utterance is sounded.

We came to the conclusion that the personal pronouns are used in the English language to express both person deixis and text/discourse deixis conveying various kinds of socially determined information about the participants in a speech event. These pronouns express information regarding the relationship between participants, social status of the addressee, formality of the conversation, respect and politeness toward the addressee, and so on. Indication, as to the thought, expressed by the speaker, is not only characteristic for the indicators, but also for the personal pronouns. The conformity as to the function of gestures and demonstrative pronouns are only the expression of initial deictic stage.

Discourse/text deixis category refers to the expressions used in the text/discourse, and also includes the statement itself. Discursion directs the referencing to the discursive part of the speaker in connection with the current environment. They refer to the discourse as a text hypothesis. That is, discursive lexical means the lexicon. Discursion refers to expressions that are played as part of a discourse. These expressions also include the words themselves. This means they are not, they do not place any participants in the discourse, nor do they point to it. The discourse deixis facilitates the understanding of the dependence of the semantic integral part of the text, and this dependence is explicitly understood by the sender. We have found out that as a whole, that discourse deixis is also called as text deixis. It involves the development of expressions within the context. When deixis is used for rhetorical purposes, it is called discourse deixis. The second person is used in the discourse deixis. Discourse $=$ text + situation, text $=$ non-situational discourse. Text is a feature occuring in the forms of writing or speaking, listening, and reading. When we analyze it, we analyze the product of this process, and the term text refers to the product itself. 


\section{References}

Bakhtin, M. M. (1986). To the philology of the action. Philology and sociology of science and technology (pp. 80-160). Yearly book, 1984-1985.

Benvenist, E. (1974). General linguistics. Progress, 448c.

Brown, P., \& Yule, G. (1988). Discourse Analysis (p. 283). Cambridge.

Bühler, K. (1990). Theory of Language: The representational function of language. Amsterdam. John Benjamins. https://doi.org/10.1075/fos.25

Chafe, W. (1994). Discourse, consciousness and time. The flow and displacement of conscious experience in speaking and writing (p. 392). Chicago: University of Chicago Press.

Demarsky, M. (1999). Problems of text formation and literary text (on the material of Russian prose XIX-XX century). SPB. Publishing house, SPbGy, 281c.

Ehlich, K. (1983). Deictic Expressions and the Connexity of Text-Amsterdam (p. 285). Philadelphia: John Benjamins.

Fillmore, C. J. (1971a). Toward a Theory of Deixis (pp. 219-242). University of Hawaii Working Papers in Linguistics.

Fillmore, C. J. (1971b). Santa Cruz Lectures on deixis (p. 268). Bloomington: Indiana University Linguistics Club.

Grenoble, L., \& Matthew, R. (1996). The Role of Deictics in Discourse Coherence: French Voici/Voila and Russian Vot/Von. Journal of Pragmatics, 25, 819-838. https://doi.org/10.1016/0378-2166(95)00011-9

Halliday, M. A. K. (1972). Sociological Aspects of Semantic Change (p. 855). Proceedings of the 11th International Congress of Linguists. Bologna: IlMulino.

Jakobson, R. (1971). Shifters, verbal categories and Russian verb. In Selected Writings of Roman Jakobson (vol. 2, Word of Language, pp. 130-147). The Hague: Mouton. https://doi.org/10.1515/9783110873269.130

Kirvalidze, H. T. (1991). Deictic means in the system of modern English and their role in the organization of the text. Autoref. Diss. ...doc.doc philology. M., 49c.

Levinson, S. C. (1983). Pragmatics (p. 420). Cambridge: Cambridge University Press. https://doi.org/10.1017/CBO9780511813313

Levinson, S. C. (2004). Deixis. In J. R. Horn \& G. Ward (Eds.), The handbook of Pragmatics (pp. 97-121). Malden: Blackwell. https://doi.org/10.1002/9780470756959.ch5

Lyons, G. (1975). Deixis as the source of reference. In Formal semantics of natural language (pp. 61-83). Cambridge: Cambridge University Press. https://doi.org/10.1017/CBO9780511897696.007

Mammadov, A. Y. (2014). Deictic representations of person in media discourse. Lodz Papers in Pragmatics, 10(2), 15. https://doi.org/10.1515/lpp-2014-0013

Muhlhauser, P., \& Harre, R. (1990). Pronouns and People; The linguistic Constructions, Social and Personal Identity (p. 303). Oxford: Cambridge, MA.

Nida, E. M. (1946). The descriptive analysis of words /E/. Linguistics, 2, 342.

Pierce, C. S. (2001). Criticism and semiotics (p. 110). Novosibirsk: Itea.

Sital, R. (2016). Deixis System in Bantawa Rai and English language (p. 31). The thesis. Faculty of education Tribhuran University, Kirtpur Kathmandu, Nepal.

Suhair Adil Abdulameer, T. A. (2019). A Pragmatic Analysis of Deixis in a Religious Text. International Journal of English Linguistics, 9(2), 292. https://doi.org/10.5539/ijel.v9n2p292

Ustin, A. K. (1995). Ratio and emotion: Structurally genetic contours of text modality. In Language and Emotions (p. 286). Volgograd: Change.

Vaynrix, Y. O. (1970). About the semantic structure of language. In New in linguistics (Vol .5, pp. 177-179). M.: Progress.

Yespersen, O. (1958). Philosophy of Grammar (Translation by V. V. Passek \& S. P. Safronova, p. 408). Publishing house Foreign literature. 


\section{Copyrights}

Copyright for this article is retained by the author, with first publication rights granted to the journal.

This is an open-access article distributed under the terms and conditions of the Creative Commons Attribution license (http://creativecommons.org/licenses/by/4.0/). 